Sustainability, Agri, Food and Environmental Research, 2014, 2(4): 54-57

ISSN: 0719-3726

Nota de investigación

\title{
Cargas polínicas en Chile y salud pública.
}

\author{
Gustavo Donoso $^{1} \&$ Pedro Mardones ${ }^{2}$ \\ FUNDAMAS: Fundación de Aerobiología medio ambiente y salud. Pérez Valenzuela 1572, of 404 \\ providencia. Santiago. Chile. \\ 1) e-mail: donoso.gustavo@gmail.com \\ 2) email: pemardo@ hotmail.com
}

La flora urbana de muchas ciudades chilenas posee más elementos exóticos que nativos, adaptadas y difundidas a lo largo de nuestro país, desde las especies nativas originarías a especies introducidas, privilegiando principalmente especies provenientes de Europa, Norte América y Australia (Romero, 2009), Sin embargo varias de estas especies son anemófilas y con antecedentes de inducir alergias, con un aumento de la expresión clínica por sensibilización al polen (Rojas et al, 1999) En Chile, los trabajos orientados a describir cargas polínicas atmosféricas han sido escasos. El primer intento de investigar y medir el polen atmosférico fue realizado por el grupo de Hoffman (1978), este trabajo, se llevó a cabo con un captador gravimétrico, lo que limitaba sus conclusiones al definir cualitativamente el polen presente y su estacionalidad. Posteriormente Rojas et al (1999) determinaron mediante métodos volumétricos la lluvia polínica de Santiago durante tres años. Ambos trabajos establecieron las bases racionales para la implementación de las baterías de alérgenos para el diagnóstico de los cuadros de alergia respiratoria en la ciudad de Santiago. Recientemente nuestro grupo de Aerobiología, con la adjudicación de fondos públicos, a través de las iniciativas FONIS (Conicyt - Ministerio de Salud de Chile), caracterizó las cargas polínicas para la ciudad de Temuco, proponiendo las especies susceptibles de generar cuadros alérgicos ${ }^{1}$ (Mardones et al., 2011), y actualmente se trabaja en determinar la sensibilidad de la población de la ciudad de Temuco a estas especies ${ }^{2}$.

Cargas Polínicas En la Ciudad de Temuco, Chile: La ciudad de Temuco está ubicada en la zona centro - sur del país ( $38^{\circ} 44^{\prime} 17^{\prime}$ S - 72 36’ 06” O), a 670 km de Santiago y a una elevación de 114 metros sobre el nivel del mar. Predomina un clima templado lluvioso con influencia mediterránea, cuya característica principal es que las precipitaciones se hacen presentes en todos los 
meses del año, concentrándose principalmente en el período invernal, siendo enero y febrero los meses más secos (Di Castri y Hajek, 1976; Amigo y Ramírez 1998), la flora urbana tiene sus orígenes de los colonos europeos, especies nativas plantadas o circundantes, pastos y malezas provenientes de áreas verdes urbanas, terrenos eriazos y praderas cercanas. Según Romero (2009), presenta 35 especies nativas (27\%) y 92 especies exóticas (73\%); de ellas, 60 especies, provienen de Europa, Asia y Eurasia, 18 especies arbóreas provienen de América del Norte y 9 de Oceanía. El monitoreo de cargas polínicas en esta ciudad, se viene realizando desde el año 2006, con un captador volumétrico de polen y esporas tipo Hirsh (1952) marca Burkard ${ }^{\circ}$, siguiendo la metodología descritas por Domínguez et al (1992).

De los pólenes registrados para la ciudad de Temuco, se seleccionaron doce especies capaces de sensibilizar el tracto respiratorio, ya sea por su potencial alergénico reconocido en la literatura, para el caso de las exóticas o cosmopolitas, o por la concentración atmosférica, como el caso de especies nativas (tabla1).

Tabla 1. Resumen comportamiento atmosférico de las doce especies registradas susceptibles de generar cuadros alérgicos.

\begin{tabular}{|c|c|c|c|c|}
\hline Especie & $\begin{array}{l}\text { Total } \\
\text { anual }\end{array}$ & $\begin{array}{l}\text { Periodo de } \\
\text { polinización }\end{array}$ & $\begin{array}{l}\text { Promedio } \\
\text { semanas }\end{array}$ & Semana peak \\
\hline & $\begin{array}{l}\text { Promedios } \\
\text { anuales } \\
\text { (granos de } \\
\text { polen/m3) }\end{array}$ & & $\begin{array}{c}\text { Peak } \\
\text { (granos } \\
\text { de } \\
\text { polen/m3) }\end{array}$ & \\
\hline Acer spp & 294,4 & Sep-nov. & 9,8 & $3^{\circ}$ Octubre \\
\hline Alnus glutinosa (L.) Gaertn & 278,6 & Jul-oct. & 20,7 & $1^{\circ}$ Agosto \\
\hline Betula pendula Roth & 501,7 & Sep-oct. & 19,5 & $4^{\circ}$ Septiembre \\
\hline Cupressus spp & $1.943,9$ & Jun-nov. & 25,8 & $2^{\circ}$ Octubre \\
\hline Myrtaceae* & 707,9 & Oct-nov. & 16,3 & $4^{\circ}$ Octubre \\
\hline Nothofagus obliqua (Mirb.) Oerst * & 840,9 & Sep-oct. & 25,6 & $4^{\circ}$ Septiembre \\
\hline
\end{tabular}


Sustainability, Agri, Food and Environmental Research, 2014, 2(4): 54-57

ISSN: 0719-3726

$\begin{array}{lrlrr}\begin{array}{l}\text { Nothofagus dombeyi (Mirb.) Oerst * } \\ \text { Ulmus spp }\end{array} & 697,3 & \text { Oct-nov. } & 19,2 & 2^{\circ} \text { Octubre } \\ \begin{array}{l}\text { Platanus acerifolia (Ait.) Willd } \\ \text { Plantanaceae }\end{array} & 352,9 & \text { Jul-sep. } & 18,6 & 2^{\circ} \text { Agosto } \\ \begin{array}{l}\text { Rumex spp } \\ \text { Poaceae }\end{array} & 516,4 & \text { Nep-oct. } & 19,4 & 1^{\circ} \text { Octubre } \\ & 1.165,6 & \text { Oct-feb. } & 22,6 & 5^{\circ} \text { Noviembre } \\ & 4.282,6 & \text { Sep-mar } & 146,1 & 2^{\circ} \text { Diciembre } \\ \end{array}$

* Especies Nativas de Chile.

Fuente: (Mardones et al, 2011)

$\mid 56$

Temuco registra una estacionalidad marcada en cuanto al registro de pólenes, varios de ellos tienen antecedentes de alergia importante (D’ Amato y Lobefalo, 1989; Peternel et al, 2007). Los pólenes de Poaceae son los más frecuentes e importantes desde el punto de vista alergénico, entre los árboles, tanto Betula pendula como el Cupressus spp son ampliamente reconocidos como alergizantes y presentan niveles significativos que podrían generar síntomas en pacientes sensibilizados. Además destacan, registros aerobilógicos de las especies nativas, como el grupo de las Mirtáceas o Nothofagus obliqua y $N$. dombeyi, quienes contribuyen entre los meses de Septiembre y Noviembre, de estas especies no hay estudios sobre su capacidad alergizante, actualmente se está estudiando la sensibilización de estas especies en la población de Temuco ${ }^{2}$.

Estos resultados proporcionan información respecto a los alérgenos relevantes para esta ciudad que deberían ser incluidos en las baterías de alérgenos utilizadas para el diagnóstico de los cuadros de alergia respiratoria. Actualmente esta información no existe y se utilizan protocolos extraídos de la literatura extranjera o de otras ciudades, como Santiago. Es muy probable que con esta información se puedan ahorrar muchos recursos, racionalizando y optimizando los gastos en extractos alergénicos para tests basados en la información local.

Un procedimiento similar se está utilizando en las ciudades de Valparaíso y Talca, ubicadas en la zona central de Chile. Valparaíso, a pesar de ser una ciudad costera destaca con una alta prevalencia la presencia de Parietaria judaica L. y en Talca son importantes las concentraciones de Ambrosia artemisiifolia L. y recientemente en los terrenos circundante a la ciudad se han 
Sustainability, Agri, Food and Environmental Research, 2014, 2(4): $54-57$

ISSN: 0719-3726

incrementado las plantaciones de Olea europaea L. Por lo tanto estas últimas especies debieran estar reflejadas en las baterías de alérgenos para cada ciudad.

\section{Bibliografía}

Amigo, J. \& C. Ramírez, 1998. Abioclimatic classification of Chile: woodland communities in the temperate zone. Plant Ecology. 136, 9-26.

D`Amato G, \& G. Lobefalo, 1989. Allergenic pollens in the southern Mediterranean area. Journal of Allergy Clinincal Immunology 83: 116-22.

Di Castri, F.,\& E. Hajek, 1976. Bioclimatología de Chile, Universidad Católica de Chile, Santiago, $128 \mathrm{pp}$.

Domínguez, E., C. Galán, F. Vollamandos, \& F. Infante 1992. Handing and evaluation of the data from the aerobiological sampling. Monografías REAN/EAN. 1: 1-18.

Hirst, J.M. 1952. “An automatic volumetric spore-trap”. Annual Applied Biology, 39:257-265.

Hoffman A.V, F. Riveros, S. Qraya, O. Rivera, G. Avila, \& G. Montenegro, 1978. Identifi cación y recuento del pólen alergénico atmosférico en el Centro de Santiago (1976-1971). Revista Médica de Chile: 106: 595-600.

Mardones, P., G. Donoso, R. Rocha, A. Córdova, \& M. Grau, 2011. Caracterización y registro del polen atmosférico en la ciudad de Temuco. Revista Chilena de Enfermedades Respiratorias 27: 7-15

Peternel R, S.M. Milanovic, I. Hrga, T. Mileta, J. Culig 2007.Incidence of Betulaceae Pollen and Pollinosis in Zagreb, Croatia, 2002-2005. Annals of Agriculture Environmental Medicine 14: 8791.

Rojas, G, J. Roure, F. Galleguillos, \& P. Mardones, 1999. Aeropalinología de Santiago. Revista Chilena de Enfermedades Respiratorias 15: 141-55.

Romero, M., S. Rebolledo \& P. Jaramillo. 2009. Árboles ornamentales de la ciudad de Temuco, Región de la Araucanía (IX), Chile. Chloris Chilensis, Año 12 №1. URL: http://www.chlorischile.cl 